\title{
DIAGNÓSTICO HIDROGEOLÓGICO E DA QUALIDADE DAS ÁGUAS SUBTERRÂNEAS DA BACIA DO RIO GRANDE - BA
}

\author{
Maíra Sampaio da Costa ${ }^{1}$; José Alexandre Araújo Nogueira ${ }^{2} \&$ Sérgio Augusto de Morais \\ Nascimento ${ }^{3}$.
}

RESUMO - O presente trabalho consiste no estudo hidrogeológico/hidrogeoquímico da bacia hidrográfica do rio Grande, que possui uma área aproximada de $75.000 \mathrm{~km}^{2}$ e está inserido no médio São Francisco no Estado da Bahia. Esta bacia é a maior su-bacia do rio São Francisco e a segunda bacia em importância na formação das vazões do rio São Francisco. Portanto, a bacia do Rio Grande e seu potencial hidroenergético estão auxiliando no crescimento agrícola do oeste baiano. O objetivo deste trabalho foi obter uma análise hidrogeológica e da qualidade das águas subterrâneas através dos dados de 31(trinta e um) poços provindos do SIAGAS (CPRM). Os resultados obtidos com o auxílio do programa Qualigraf juntamente com os parâmetros propostos pela Portaria 2914/11 possibilitaram classificar e estabelecer a qualidade das águas subterrâneas e indicar a sua potabilidade para o consumo humano, indicando os melhores poços tubulares encontrados na região.

ABSTRACT - This present work consists in the hydrogeological/hydrogeochemical study of the Grande River's basin that has an area approximately of $75.000 \mathrm{~km}^{2}$ and it is inserted of the São Francisco middle of the Bahia State. This basin is the biggest sub-basin of the São Francisco's river and the second basin in importance in the formation of the outflows of the São Francisco's river. Thus, Grande River's basin and its hydrogeological potential have help in the growth agricultural of the baiano west. The objective of this work was gain hydrogeological analysis and of the underground waters' qualities through the databank of 31 (thirty one) tube wells offered by SIAGAS (CPRM). The results gain with the help of the Qualigraf program along with the parameters proposed by Portaria 2914/11 allowed to grade and establish the qualities of the underground waters and to indicate its drinkability for the human use, indicating the best tube wells founded in the area.

Palavra-chave- Águas Subterrâneas, bacia, qualidade das águas, SIAGAS. 1UFBA: Campus de Ondina - Portaria 03, R. Barão de Jeremoabo, S/N - Ondina, Salvador - BA, 40170-290; tel: (71)996125676; email: mairasampaio42@gmail.com.

2UFBA: Campus de Ondina - Portaria 03, R. Barão de Jeremoabo, S/N - Ondina, Salvador - BA, 40170-290; tel: (71) 994012637; email: ja.nogueira@ hotmail.com

3UFBA: Campus de Ondina - Portaria 03, R. Barão de Jeremoabo, S/N - Ondina, Salvador - BA, 40170-290; tel: 32838587; email: sergiomn@ufba.br XIX Congresso Brasileiro de Águas Subterrâneas 


\section{1- INTRODUÇÃO}

A bacia hidrográfica do rio Grande localiza-se na região oeste do estado da Bahia e possui aproximadamente $75.000 \mathrm{Km}^{2}$ de área e representa $12,6 \%$ da área de drenagem do Rio São Francisco, sendo a sua maior sub-bacia. A bacia do Rio Grande tem sua nascente nas proximidades da divisa entre Bahia e Goiás e percorre 502km até desaguar no Rio São Francisco, no município de Barra. (MOREIRA; SILVA, 2010).

A bacia hidrográfica do rio Grande possui sete sub-bacias: Rio Preto; Rio Branco; Rio de Ondas; Rio de Fêmeas; Alto Rio Grande; Rio São Desiderio e Rio Tamanduá ou Boa Sorte (INEMA, 2012). O Rio Grande corre em direção geral SO-NE e possui padrão de drenagem meandrante. Este recebe seus principais tributários pela margem esquerda, sendo eles os rios: Das Fêmeas, de Ondas, Branco e Preto, com áreas de drenagem de $6.211 \mathrm{~km} 2,5.391 \mathrm{~km} 2,8.045$ km2; e $22.091 \mathrm{~km} 2$ respectivamente (MOREIRA; SILVA, 2010).

A partir da análise de três estações pluviométricas obtidas no ANA (Agência Nacional de Águas), Boqueirão, Formoso e Barreiras, observa-se que as vazões na bacia hidrográfica do rio Grande são contrastantes. Identificou-se que no ano de 2011 ocorreu o ápice das vazões anuais de todas as três estações, quando provavelmente existiu um índice de pluviosidade maior nesta região. A vazão média anual em Boqueirão atingiu cerca de $270 \mathrm{~m}^{3} / \mathrm{s}$, sendo esta a maior vazão encontrada desta análise; a estação de Formosa chegou a obter mais que $92 \mathrm{~m}^{3} / \mathrm{s}$, e por fim, no mesmo ano Barreiras atingiu médias de $70 \mathrm{~m} 3 / \mathrm{s}$. A vazão total outorgada superficialmente na bacia hidrográfica do rio Grande foi definida por Almeida \& Moreira (2014) como de $38,89 \mathrm{~m}^{3} \mathrm{~s}^{-1}$.

São identificados três climas diferentes na bacia hidrográfica do rio Grande: úmido no extremo Oeste da bacia que apresenta índice pluviométrico acima de $1.700 \mathrm{~mm}$; subúmido na região central da bacia; e seminário a parte oriental da bacia que são verificados índices pluviométricos inferiores a $800 \mathrm{~mm}$, sendo comuns em períodos de secas (MOREIRA; SILVA, 2010).

A bacia hidrográfica do Rio Grande é caracterizada por apresentar contrastes bruscos de altimetria, possuindo no setor oeste altimetrias muito mais elevadas que chegam a atingir 1087m e no setor leste um baixo topográfico com mínima de 350m. Desta forma, foi divido a área em cinco unidades geomorfológicas: chapada, patamares, depressões, serras e tabuleiros, em que a maior extensão é formada por chapadas e depressões situadas a oeste e nordeste respectivamente. A bacia 
possui declividade de $10 \%$ a $43 \%$ que equivale a $4,5^{\circ}$ a $19,7^{\circ}$ (Leal et al, 2003). Esta possui expressiva diversidade geológica sendo constituída principalmente pelo Grupo Bambuí, Grupo Urucuia, Grupo Rio Preto e Formação Sítio Novo (JUNIOR; LIMA, 2007).

A bacia do Rio Grande é a segunda bacia em importância para formação das vazões do Rio São Francisco e possui relevo favorável para a agricultura, o que evidencia seu grande papel para o crescimento hidroenergético, proporcionando o rápido crescimento agrícola do Oeste baiano, principalmente no momento em que se realiza o projeto de transposição da bacia do Rio São Francisco (MOREIRA; SILVA, 2010). Hoje, a região é a fatia com maior expressividade no agronegócio da Bahia, com matriz produtiva diversificada, tecnologia e qualidade (ALMEIDA; MOREIRA, 2014).

Desta forma, este presente trabalho possui o objetivo de classificar e estabelecer a partir da hidrogeologia a qualidade das águas subterrâneas que vem sendo continuamente explorada tanto pela agroindústria quanto pela população local, utilizando-se do programa Qualigraf (2014) e Portaria 2914 / 2011. E, por conseguinte, identificar e classificar os poços mais adequados para o consumo humano e irrigação das águas subterrâneas da bacia hidrográfica do rio Grande.

\section{2- ÁREA DE ESTUdO}

A bacia hidrográfica do rio Grande se localiza entre as latitudes $10^{\circ} 50^{\prime}$ e $13^{\circ} 00^{\prime}$ sul e longitudes $45^{\circ} 25^{\prime}$ e $45^{\circ} 30^{\prime}$ 'W.Gr. Está contido no noroeste do Estado da Bahia, na margem esquerda do rio São Francisco (LEAL et al, 2003). O rio São Francisco pode ser dividido em três regiões: alto, médio e baixo; da qual a bacia do rio Grande se encontra localizado no médio São Francisco. A bacia hidrográfica do rio Grande faz limites geográficos ao norte com o estado do Piauí, ao sul com a bacia do rio Corrente, a oeste com os estados de Goiás e Tocantins e a leste com as bacias da calha do médio São Francisco (Figura 1) (INEMA, 2008).

De acordo com o IBGE (2009), cerca de 1,864,000 pessoas vivem nos munícipios que compõem a bacia hidrográfica do rio Grande. A economia desta região é baseada principalmente na atividade de agricultura (soja, milho, algodão, frutas, entre outros) (SILVA; MOREIRA, 2010). O município de Luís Eduardo Magalhães contido na bacia hidrográfica do rio Grande e próximo do estado de Tocantins é responsável por $60 \%$ da produção de grãos do Estado. Neste município, são cultivados mais de 270 mil hectares, dos quais o plantio da soja ocupa área superior a 175 mil 
(PREFEITURA LEM, 2009). Outro exemplo é o município de São Desidério, considerado o maior produtor de algodão do País (AIBA, 2009).

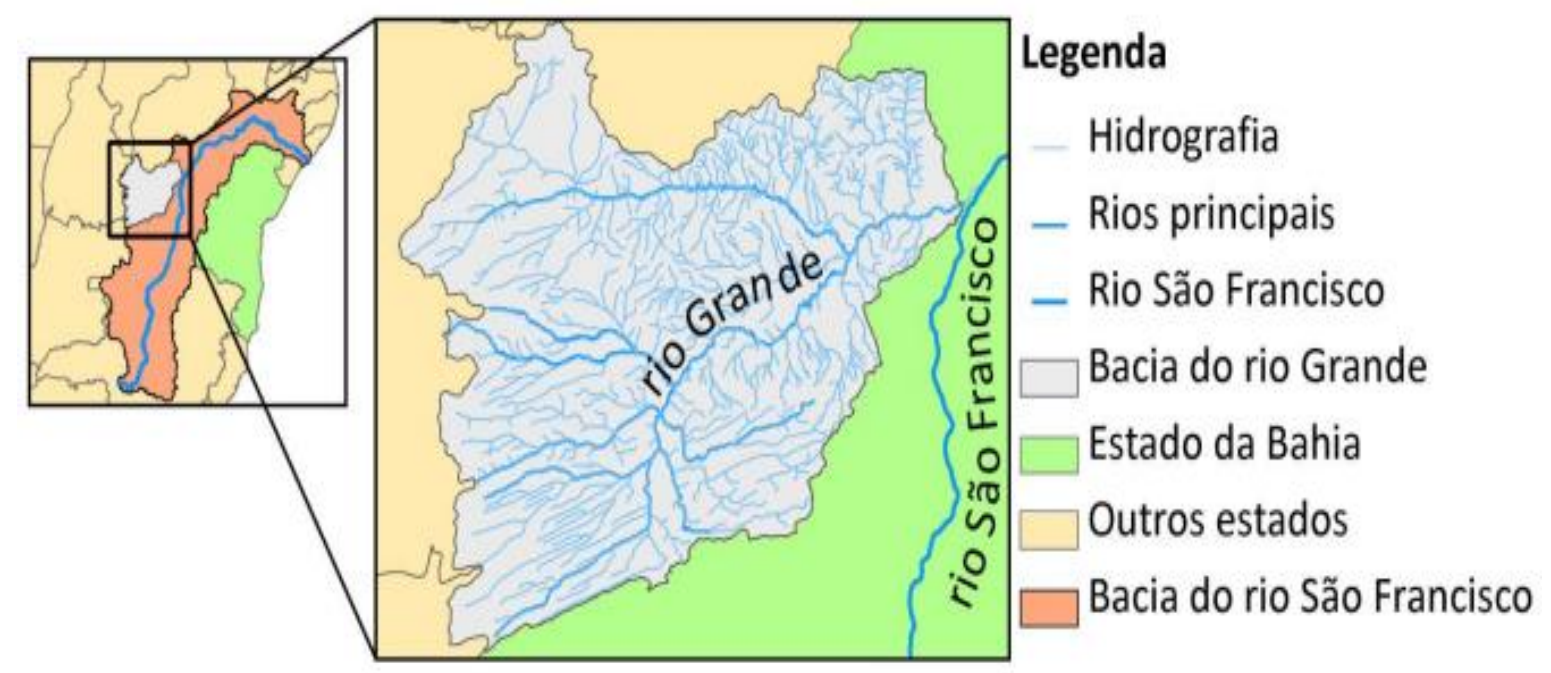

Figura 1. Localização da Bacia do rio Grande em relação à Bacia do Rio São Francisco

Fonte: ALMEIDA; MOREIRA, 2014.

\section{3- OBJETIVOS}

- Fazer a análise hidrogeológica e da qualidade das águas subterrâneas utilizando o programa Qualigraf;

- Classificar e estabelecer a qualidade das águas subterrâneas utilizando-se a Portaria 2914/2011 do Ministério da Saúde.

\section{2- MATERIAIS E MÉTODOS}

Para obter os resultados hidrogeológicos e da qualidade das águas subterrâneas da Bacia do Rio Grande, foi delimitado pelo ARCGIS os dezoito municípios contidos totalmente ou parcialmente na Bacia do rio Grande: Angical, Baianópolis, Barra, Barreiras, Brejolândia, Buritirama, Catolândia, Cotegipe, Cristópolis, Formosa do Rio Preto, Luís Eduardo Magalhães, Mansidão, Muquém do São Francisco, Riachão das Neves, Santa Rita de Cássia, São Desidério, Tabocas do Brejo Velho e Wanderley. 
Após, utilizando-se do banco de dados da CPRM (SIAGAS) foram analisados os poços destes municípios e apenas 27 poços possuíam as informações necessárias para as análises químicas (Figura 2).

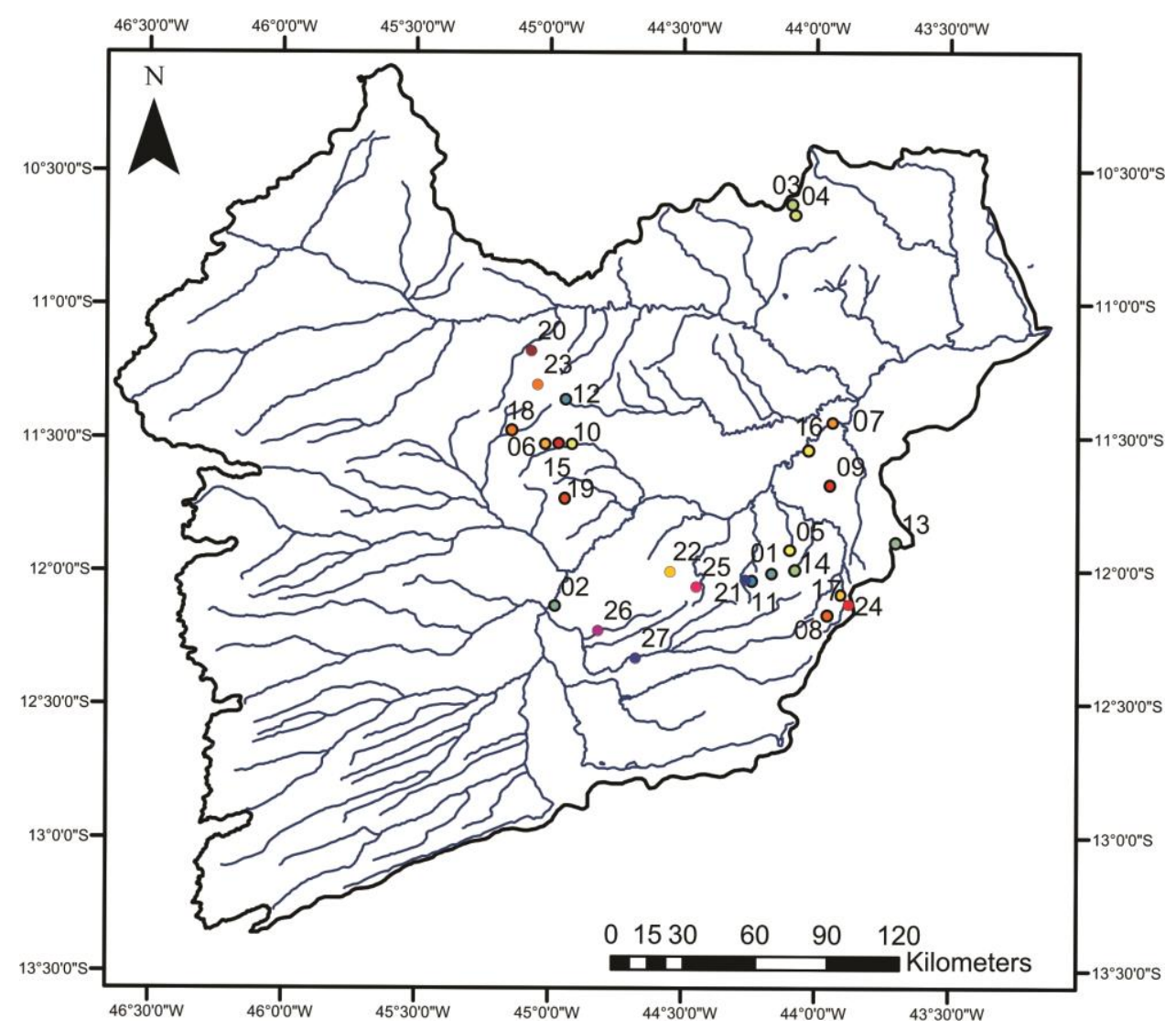

Figura 2. Mapa de amostragem na bacia do rio Grande

Estes poços foram exportados do Excel para o formato do programa Qualigraf. Neste programa, foi possível estabelecer o balanço iônico, o erro analítico e a salinidade das águas. Foi possível também classifica-los no Diagrama de Piper e Lemoine. Desta forma, correlacionando os parâmetros encontrados nas águas subterrâneas com a portaria n²914 / 11 definem-se a qualidade das águas e indicado o melhor poço para consumo humano.

Por fim, levantamentos bibliográficos da bacia hidrográfica em estudo foram realizados. As informações copiladas foram sintetizadas, interpretadas e estabelecidas conclusões sobre a importância dos recursos hídricos subterrâneos na bacia hidrográfica do rio Grande. 


\section{3- RESULTADOS E DISCUSSÕES}

A partir do programa Qualigraf (2014) foi possível caracterizar as águas dos poços da bacia do rio Grande. Foi executado o balanço iônico e erro analítico, a classificação das águas através do diagrama de Piper e classificação por irrigação. Além disto, foi indicada a salinidade das águas e estabelecida a qualidade das águas (potabilidade), apontando os melhores poços para o consumo humano.

\section{1- Balanços iônicos e cálculo do erro analítico}

O cálculo do erro analítico pode ser estimado a partir do balanço iônico, baseado no fato de que numa análise química de água a concentração total (expressa em meq/L) dos cátions deve ser aproximadamente igual a dos ânions. A diferença de valores apresentados é classificada como erro analítico (SIMÕES, 2008). O balanço iônico e erro analítico dos poços da bacia do Rio Grande encontram-se na Tabela 1.

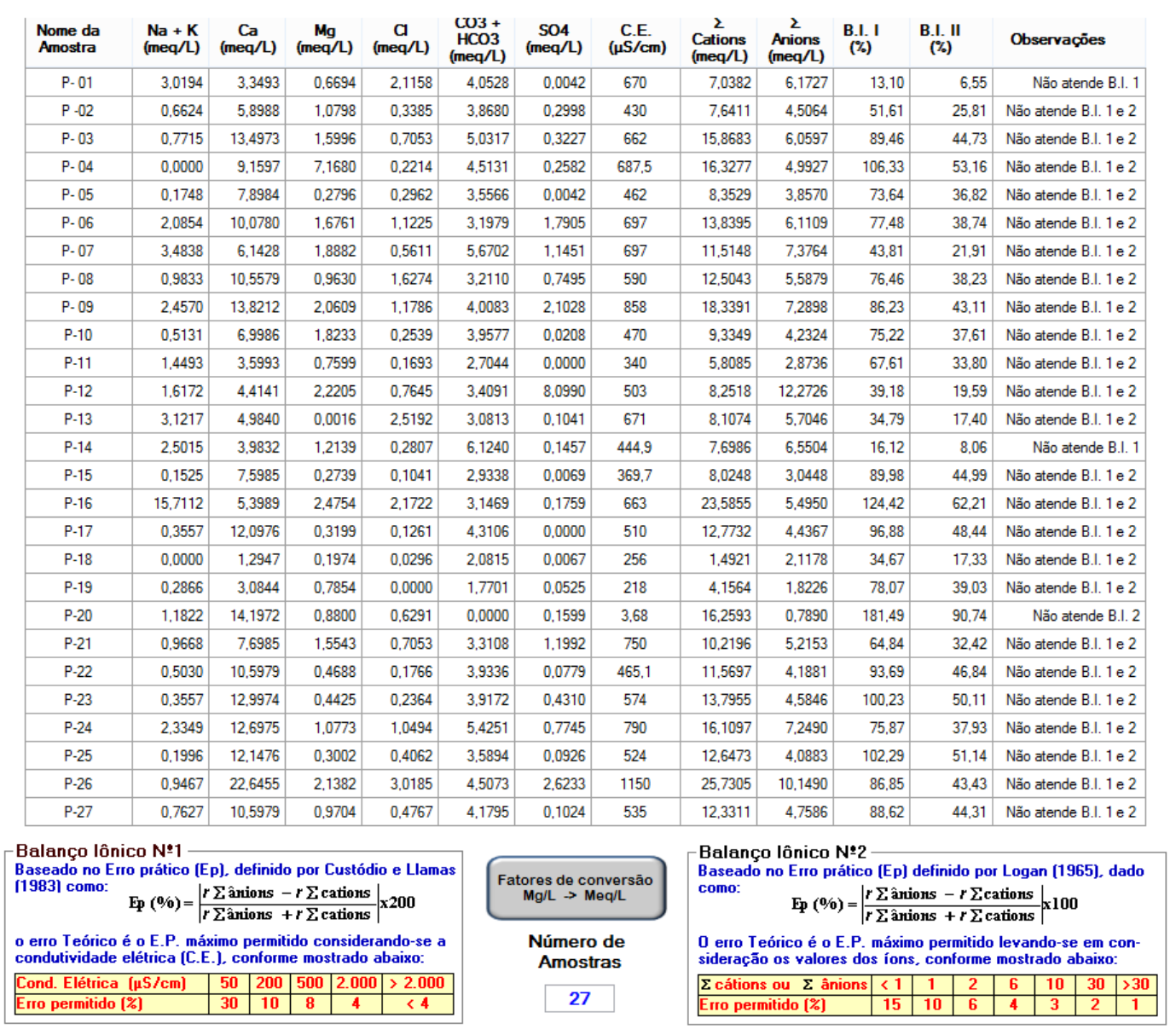

Tabela 1. Balanço Iônico e erro analítico nas águas subterrâneas da bacia do Rio Grande 
A tabela 1 mostra que a maioria dos poços não atente aos critérios necessários dos balanços iônicos com exceção dos os poços P-01, P-14 e P-20. Relacionando estes poços a geologia associada, tem-se que os P-01 e P-14 estão relacionados ao Grupo Bambuí e o poço P-20 está relacionado a rochas cristalinas não identificadas.

\section{2- Classificações de Piper das águas subterrâneas}

O Diagrama de Piper é usualmente usado para fins de classificação e comparação de diferentes grupos de águas quanto aos íons dominantes. A representação gráfica possibilita estabelecer as relações iônicas e ressaltar variações temporais ou espaciais existentes (FUNCEME, 2007). Desta maneira, foi possível estabelecer a classificação das águas subterrâneas da Bacia do rio Grande, figura 3:

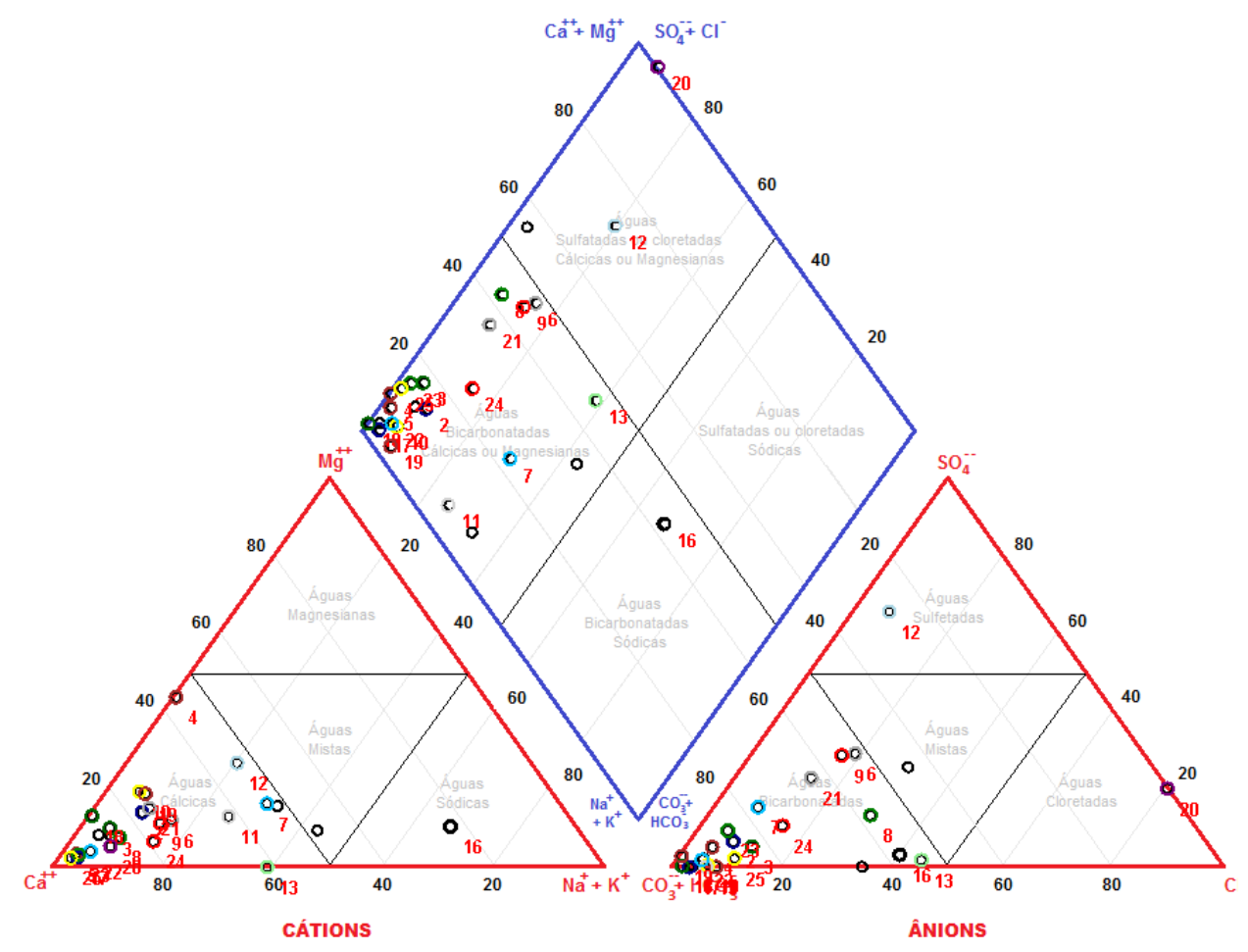

Figura 3. Diagrama triangular de Piper da bacia do rio Grande. 
A partir do diagrama de Piper foi possível observar que as águas subterrâneas são preferencialmente cálcicas bicabornatadas já que a maioria dos poços se encontra neste intervalo. Além disto, observa-se que prevalece a associação com o Grupo Bambuí para esse agrupamento de poços. Secundariamente, as águas podem ser classificadas como cloretadas-cálcicas representados pelos poços P-12 e P-20 que geologicamente se situam no Grupo Santo Onofre e rocha cristalina não identificada, respectivamente. Por fim, foi identificado um exemplar das águas sódicas bicabornatadas a partir do poço P-16 que se associa geologicamente ao Grupo Bambuí.

É observada na Tabela 2 a classificação das águas para cada poço separadamente e na Tabela 3 a porcentagem que ocupa cada classificação. Nesta última, percebe-se que as águas cálcicas bicaborn atadas equivalem a $81 \%$ do total confirmando o resultado obtido pelo diagrama de Piper.

\begin{tabular}{|c|c|c|c|c|c|c|c|c|}
\hline № & $\begin{array}{l}\text { Nome da } \\
\text { Amostra }\end{array}$ & $\begin{array}{l}\mathrm{Na}+\mathrm{k} \\
(\mathrm{mg} / \mathrm{L})\end{array}$ & $\underset{(\mathrm{mg} / \mathrm{L})}{\mathrm{Ca}}$ & $\underset{(m g / L)}{\mathrm{Mg}}$ & $\underset{(m g / L)}{\mathrm{C}}$ & $\begin{array}{c}\mathrm{CO} 3+\mathrm{HCO} 3 \\
(\mathrm{mg} / \mathrm{L})\end{array}$ & $\begin{array}{c}\mathrm{SO} 4 \\
(\mathrm{mg} / \mathrm{L})\end{array}$ & $\begin{array}{c}\text { Classificação } \\
\text { das Águas }\end{array}$ \\
\hline 1 & P- 01 & 70,40 & 67.00 & 8.14 & 75,00 & 223,50 & 0,20 & Mista Bicarbonatada \\
\hline 2 & $P-02$ & 15,64 & 118,00 & 13,13 & 12,00 & 236,00 & 14,40 & Cálcica Bicarbonatada \\
\hline 3 & P. 03 & 18.46 & 270,00 & 19.45 & 25,00 & 307.00 & 15,50 & Cálcica Bicarbonatada \\
\hline 4 & P. 04 & 0.00 & 183,23 & 87.16 & 7.85 & 227,10 & 12,40 & Cálcica Bicarbonatada \\
\hline 5 & P. 05 & 4,20 & 158,00 & 3.40 & 10,50 & 217,00 & 0,20 & Cálcica Bicarbonatada \\
\hline 6 & P. 06 & 48,60 & 201,60 & 20,38 & 39.79 & 165,53 & 86,00 & Cálcica Bicarbonatada \\
\hline 7 & P. 07 & 81,20 & 122,88 & 22,96 & 19.89 & 300,46 & 55.00 & Cálcica Bicarbonatada \\
\hline 8 & P. 08 & 23.10 & 211.20 & 11.71 & 57,69 & 195.91 & 36,00 & Cálcica Bicarbonatada \\
\hline 9 & P. 09 & 57.10 & 276,48 & 25.06 & 41,78 & 203.61 & 101.00 & Cálcica Bicarbonatada \\
\hline 10 & P-10 & 12,52 & 140,00 & 22,17 & 9.00 & 227,00 & 1,00 & Cálcica Bicarbonatada \\
\hline 11 & P-11 & 33,96 & 72,00 & 9,24 & 6.00 & 165,00 & 0,00 & Cálcica Bicarbonatada \\
\hline 12 & P-12 & 38,00 & 88,30 & 27,00 & 27,10 & 208,00 & 389,00 & Cálcica Sulfatada \\
\hline 13 & P-13 & 73,00 & 99,70 & 0,02 & 89,30 & 188,00 & 5,00 & Cálcica Bicarbonatada \\
\hline 14 & P-14 & 58.00 & 79,68 & 14,76 & 9.95 & 255,34 & 7,00 & Cálcica Bicarbonatada \\
\hline 15 & P-15 & 4,00 & 152,00 & 3,33 & 3,69 & 179,00 & 0,33 & Cálcica Bicarbonatada \\
\hline 16 & P-16 & 362,00 & 108,00 & 30,10 & 77,00 & 192,00 & 8.45 & Sódica Bicarbonatada \\
\hline 17 & P-17 & 9,00 & 242,00 & 3,89 & 4,47 & 263,00 & 0,00 & Cálcica Bicarbonatada \\
\hline 18 & P-18 & 0,00 & 25,90 & 2,40 & 1,05 & 127,00 & 0,32 & Cálcica Bicarbonatada \\
\hline 19 & P-19 & 7,00 & 61,70 & 9,55 & 0,00 & 108,00 & 2,52 & Cálcica Bicarbonatada \\
\hline 20 & $P-20$ & 28,00 & 284,00 & 10,70 & 22,30 & 0,00 & 7,68 & Cálcica Cloretada \\
\hline 21 & P-21 & 22,72 & 154,00 & 18,90 & 25,00 & 202,00 & 57,60 & Cálcica Bicarbonatada \\
\hline 22 & P-22 & 12,80 & 212,00 & 5,70 & 6.26 & 240,00 & 3,74 & Cálcica Bicarbonatada \\
\hline 23 & P-23 & 9,00 & 260,00 & 5,38 & 8,38 & 239,00 & 20,70 & Cálcica Bicarbonatada \\
\hline 24 & $P-24$ & 54,50 & 254,00 & 13,10 & 37,20 & 331,00 & 37,20 & Cálcica Bicarbonatada \\
\hline 25 & $P-25$ & 5,00 & 243,00 & 3,65 & 14,40 & 219,00 & 4,45 & Cálcica Bicarbonatada \\
\hline 26 & P-26 & 23,00 & 453,00 & 26,00 & 107,00 & 275,00 & 126,00 & Cálcica Mista \\
\hline 27 & P-27 & 19,80 & 212,00 & 11,80 & 16,90 & 255,00 & 4,92 & Cálcica Bicarbonatada \\
\hline
\end{tabular}

Tabela 2. Classificação das águas da bacia do rio Grande 


\begin{tabular}{|c|c|c|c|c|c|}
\hline Classes das Águas & № & $\%$ & Classes das Águas & № & $\%$ \\
\hline Sódicas cloretadas & 0 & 0 & Magnesianas cloretadas & 0 & 0 \\
\hline Sódicas Bicarbonatadas & 1 & 4 & Magnesianas Bicarbonatadas & 0 & 0 \\
\hline Sódicas Sulfatadas & 0 & 0 & Magnesianas Sulfatadas & 0 & 0 \\
\hline Sódicas Mistas & 0 & 0 & Magnesianas Mistas & 0 & 0 \\
\hline Cálcicas cloretadas & 1 & 4 & cloretadas Mistas & 0 & 0 \\
\hline Cálcicas Bicarbonatadas & 22 & 81 & Bicarbonatadas Mistas & 1 & 4 \\
\hline Cálcicas Sulfatadas & 1 & 4 & Sulfatadas Mistas & 0 & 0 \\
\hline Cálcicas Mistas & 1 & 4 & Mistas & 0 & 0 \\
\hline
\end{tabular}

\begin{tabular}{|c|c|c|c|c|c|}
\hline Classes das Águas & № & $\%$ & Classes das Águas & № & $\%$ \\
\hline Sódicas & 1 & 4 & Cloretadas & 1 & 4 \\
\hline Cálcicas & 25 & 93 & Bicarbonatadas & 24 & 89 \\
\hline Magnesianas & 0 & 0 & Sulfatadas & 1 & 4 \\
\hline Mistas (Cátions) & 1 & 4 & Mistas (ânions) & 1 & 4 \\
\hline
\end{tabular}

Tabela 3. Distribuição das classes das águas.

\section{3- Salinidade}

Os sólidos Totais Dissolvidos (STD) representam o peso total dos constituintes minerais presentes na água, por unidade de volume. Na maior parte das águas naturais, a Condutividade Elétrica (CE) da água, multiplicada por um fator que varia entre 0.55 e 0.75 , gera uma boa estimativa de STD. A partir dos dados obtidos de STD as águas subterrâneas foram classificadas em Doces, Salobras ou Salgadas (FUNCEME, 2007). Os valores de STD juntamente com a classificação das águas da bacia do rio Grande estão indicados na tabela 4. 


\begin{tabular}{|c|c|c|c|c|c|c|c|c|c|}
\hline $\begin{array}{l}\text { Nome da } \\
\text { Amostra }\end{array}$ & $\begin{array}{l}\mathrm{Na}+\mathrm{K} \\
(\mathrm{mg} / \mathrm{L})\end{array}$ & $\underset{(\mathrm{mg} / \mathrm{L})}{\mathrm{Ca}}$ & $\underset{(\mathrm{mg} / \mathrm{L})}{\mathrm{Mg}}$ & $\underset{(\mathrm{mg} / \mathrm{L})}{\mathrm{Cl}}$ & $\begin{array}{l}\mathrm{CO} 3+ \\
\mathrm{HCO} 3 \\
(\mathrm{mg} / \mathrm{L})\end{array}$ & $\begin{array}{c}\text { SO4 } \\
\text { (mg/L) }\end{array}$ & $\begin{array}{l}\text { C.E. } \\
(\mu \mathrm{S} / \mathrm{cm})\end{array}$ & $\begin{array}{c}\text { STD } \\
\text { estimado } \\
\text { (mg/L) }\end{array}$ & Classificação \\
\hline P. 01 & 70,40 & 67,00 & 8,14 & 75,00 & 223,50 & 0,20 & 670 & 435,5 & Agua Doce \\
\hline$P-02$ & 15,64 & 118,00 & 13,13 & 12,00 & 236,00 & 14,40 & 430 & 279,5 & Agua Doce \\
\hline P. 03 & 18,46 & 270,00 & 19,45 & 25,00 & 307,00 & 15,50 & 662 & 430,3 & Agua Doce \\
\hline P. 04 & 0,00 & 183,23 & 87,16 & 7,85 & 227,10 & 12,40 & 687,5 & 446,9 & Água Doce \\
\hline P. 05 & 4,20 & 158,00 & 3,40 & 10,50 & 217,00 & 0,20 & 462 & 300,3 & Água Doce \\
\hline P. 06 & 48,60 & 201,60 & 20,38 & 39,79 & 165,53 & 86,00 & 697 & 453,1 & Agua Doce \\
\hline P. 07 & 81,20 & 122,88 & 22,96 & 19,89 & 300,46 & 55,00 & 697 & 453,1 & Agua Doce \\
\hline P. 08 & 23,10 & 211,20 & 11,71 & 57,69 & 195,91 & 36,00 & 590 & 383,5 & Agua Doce \\
\hline P. 09 & 57,10 & 276,48 & 25,06 & 41,78 & 203,61 & 101,00 & 858 & 557,7 & Agua Salobra \\
\hline P-10 & 12,52 & 140,00 & 22,17 & 9,00 & 227,00 & 1,00 & 470 & 305,5 & Agua Doce \\
\hline P-11 & 33,96 & 72,00 & 9,24 & 6,00 & 165,00 & 0,00 & 340 & 221,0 & Água Doce \\
\hline P-12 & 38,00 & 88,30 & 27,00 & 27,10 & 208,00 & 389,00 & 503 & 327,0 & Agua Doce \\
\hline P.13 & 73,00 & 99,70 & 0,02 & 89,30 & 188,00 & 5,00 & 671 & 436,2 & Água Doce \\
\hline P-14 & 58,00 & 79,68 & 14,76 & 9,95 & 255,34 & 7,00 & 444,9 & 289,2 & Água Doce \\
\hline P-15 & 4,00 & 152,00 & 3,33 & 3,69 & 179,00 & 0,33 & 369.7 & 240,3 & Agua Doce \\
\hline P-16 & 362,00 & 108,00 & 30,10 & 77,00 & 192,00 & 8.45 & 663 & 431,0 & Agua Doce \\
\hline P-17 & 9,00 & 242,00 & 3,89 & 4,47 & 263,00 & 0,00 & 510 & 331,5 & Agua Doce \\
\hline P-18 & 0,00 & 25,90 & 2,40 & 1,05 & 127,00 & 0,32 & 256 & 166,4 & Água Doce \\
\hline P.19 & 7,00 & 61,70 & 9,55 & 0,00 & 108,00 & 2,52 & 218 & 141,7 & Água Doce \\
\hline P-20 & 28,00 & 284,00 & 10,70 & 22,30 & 0,00 & 7,68 & 3,68 & 2,4 & Agua Doce \\
\hline $\mathrm{P}-21$ & 22,72 & 154,00 & 18,90 & 25,00 & 202,00 & 57,60 & 750 & 487,5 & Agua Doce \\
\hline P-22 & 12,80 & 212,00 & 5,70 & 6.26 & 240,00 & 3,74 & 465,1 & 302,3 & Agua Doce \\
\hline P-23 & 9,00 & 260,00 & 5,38 & 8,38 & 239,00 & 20,70 & 574 & 373,1 & Agua Doce \\
\hline P-24 & 54,50 & 254,00 & 13,10 & 37,20 & 331,00 & 37,20 & 790 & 513,5 & Agua Salobra \\
\hline P-25 & 5,00 & 243,00 & 3,65 & 14,40 & 219,00 & 4,45 & 524 & 340,6 & Água Doce \\
\hline P-26 & 23,00 & 453,00 & 26,00 & 107,00 & 275,00 & 126,00 & 1150 & 747,5 & Água Salobra \\
\hline P-27 & 19,80 & 212,00 & 11,80 & 16,90 & 255,00 & 4,92 & 535 & 347,8 & Agua Doce \\
\hline
\end{tabular}

Tabela 4. Salinidade das águas da bacia do rio Grande.

A partir da tabela 4, observa-se que a maioria dos poços foi classificada como águas doces e estão associados em sua maioria ao Grupo Bambuí e os únicos poços inapropriados para o consumo humano composto por águas salobras são os poços P-09, P-24 e P-26. Na figura 4 abaixo, é possível observar que as águas doces compõem $88,9 \%$ dos poços em estudo e a salobra 11,4\%. 

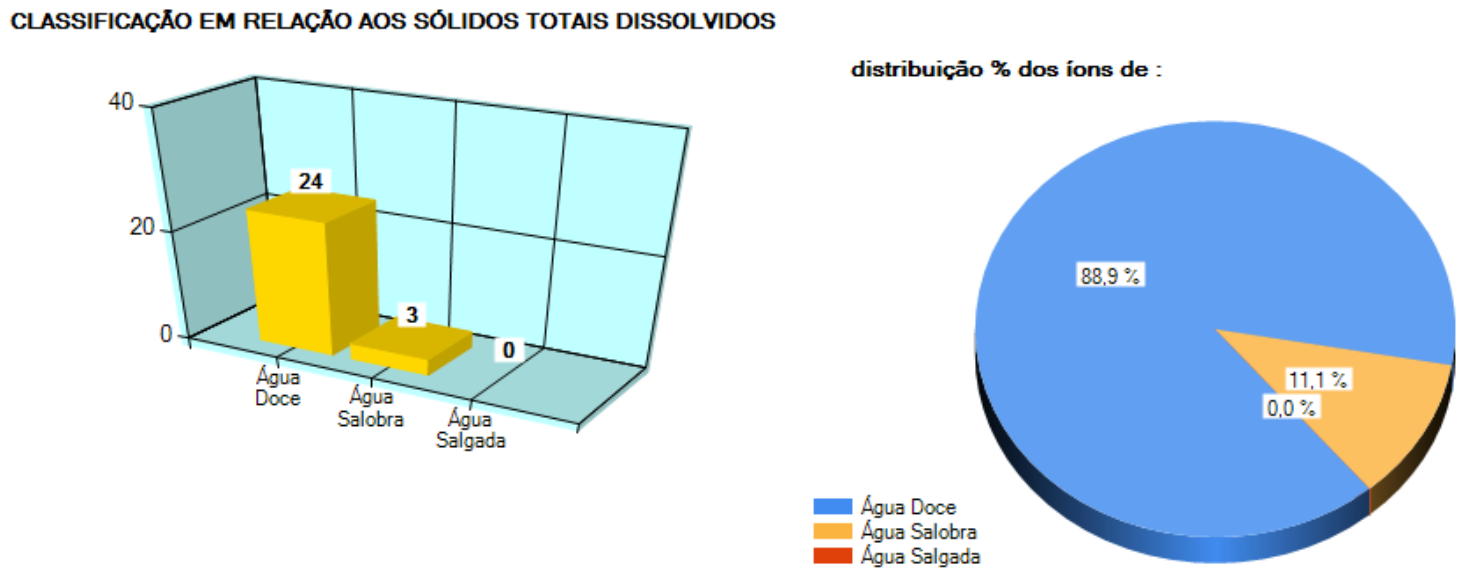

Figura 4. Classificação em relação à salinidade - Bacia do Rio Grande

\section{4- Classificações das águas subterrâneas para irrigação}

A classificação das águas para irrigação é apresentada pela concentração de íons como o sódio, cálcio e magnésio, além de parâmetros a Condutividade Elétrica (FUNCEME, 2007). Esta classificação tem como finalidade verificar a salinidade presente e indicar as restrições de uso destas águas para solos. A classificação por irrigação pode ser vista na figura 5. 


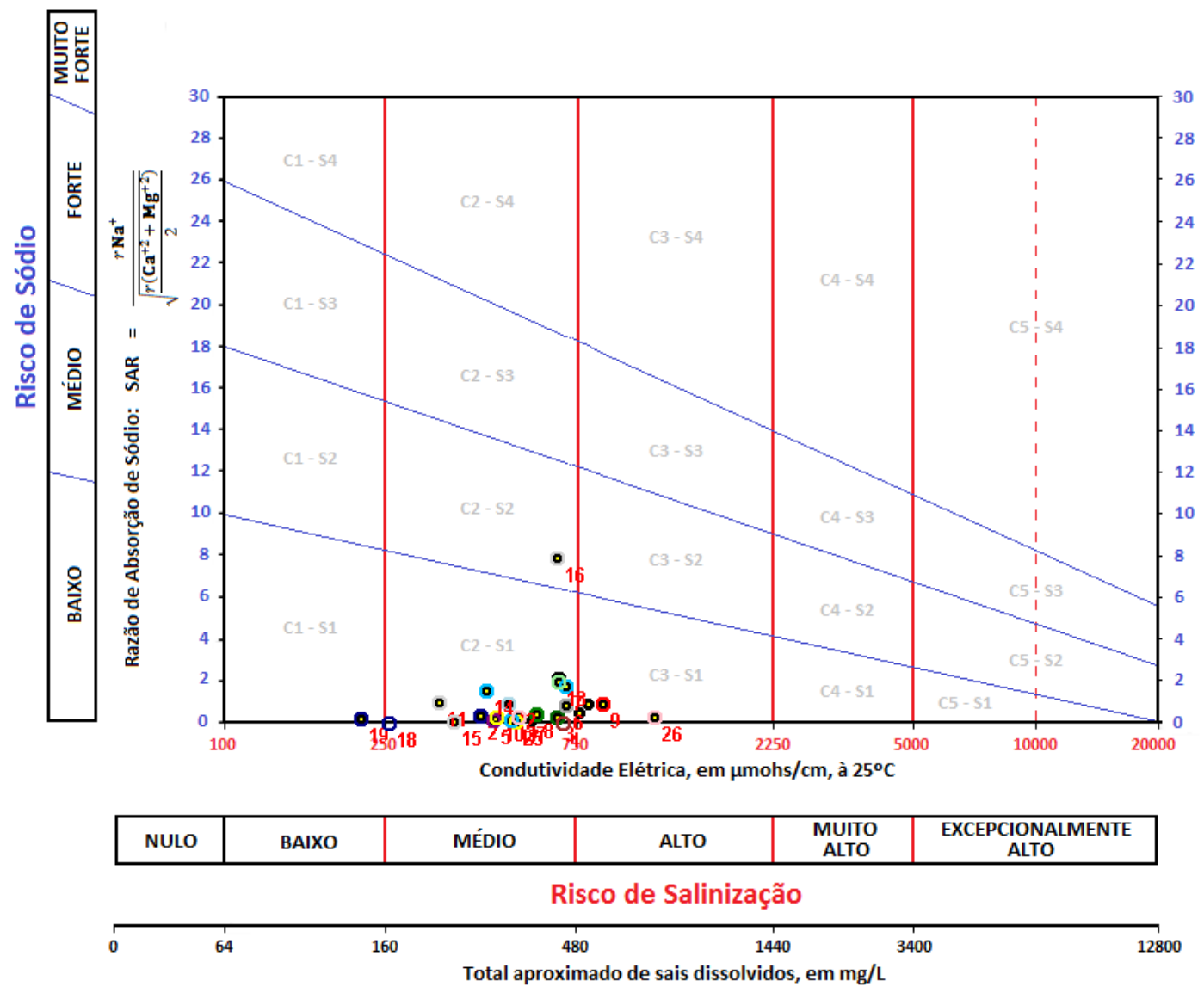

Figura 5. Classificação para irrigação - Bacia do rio Grande.

A maioria dos poços foi inserida como $\mathrm{C} 2$ - S1, em que $\mathrm{C} 2$ consiste em água com salinidade média, podendo ser usada em solos moderadamente permeáveis e S1 trata-se de água possuindo baixo teor de sódio, de uso normal em qualquer tipo de solo. Todavia, os poços considerados mais indicados para irrigação, são os poços P-18 e P-19 que pertencem ao Grupo Santo Onofre e Bambuí respectivamente, e se encontram inseridos na categoria $\mathrm{C} 1-\mathrm{S} 1$, em que $\mathrm{C} 1$ são águas de baixa salinidade que pode ser usado para irrigar a maioria das culturas e solos, apresentando baixo risco de salinização, e S1 são águas de baixo teor de sódio, de uso normal em qualquer tipo de solo. Ainda foram obtidos um poço na categoria C2-S2 (P-16) e um poço em C3-S1 (P-26). Estes poços se encontram em categorias menos indicadas para irrigação por apresentar maiores teores de sódio e águas com mais alta salinidade. 


\section{5- Qualidades das águas e Potabilidade}

A Portaria MS 2914 de 2011 (do Ministério da Saúde) define a partir de parâmetros químicos se a qualidade de uma determinada água é apropriada para o consumo humano ou não. Desta forma, foram selecionados alguns parâmetros encontrados e definidos na portaria $\mathrm{n}^{\circ} 2914$, sendo eles respectivamente: sódio, nitrato, nitrito, sulfato e turbidez. A partir desta comparação pode-se perceber que os únicos poços na bacia em estudo que não atendem aos parâmetros selecionados foram P-12, P-16 e P-26; dos quais o primeiro não atende ao parâmetro estabelecido para o sulfato, e os dois últimos não estão em conformidade com o valor de turbidez. Por outro lado podem-se estabelecer os dois melhores poços utilizando-se dos dados obtidos na classificação das águas subterrâneas para irrigação, na classificação indicada pelo diagrama de Piper e pela classificação dos sólidos totais (STD). Desta forma, observou-se que os poços mais indicados são o P-18 e P-19 que se encontram inseridos na categoria C1-S1 de irrigação e são consideradas águas doces classificadas como cálcica bicabornatadas. Estes poços se encontram geologicamente situados no Grupo Santo Onofre (P-18) e Grupo Bambuí (P-19) e são pertencentes geomorfologicamente às unidades das Chapadas e Patamares. Pode-se relacionar, portanto, que a região constituída por relevos de Chapadas e Patamares (principalmente), onde a maioria dos poços analisados está inserida, pode ser indicativo como águas indicadas para irrigação e poços indicados para o consumo humano.

\section{6- Associações entre íons e a salinidade}

O programa Qualigraf possibilita o ajuste de equações que buscam a melhor relação existente entre os íons estudados. A qualidade deste ajuste é obtida pelo coeficiente de determinação $\mathrm{R}^{2}$. Desta forma, foram realizadas correlações entre os parâmetros analisados na água fixando o C.E. No eixo $\mathrm{x}$ e variando o eixo $\mathrm{y}$. Os resultados indicaram que o elemento que tem maior representatividade para condutividade elétrica é o $\mathrm{Cl}$ com $\mathrm{R}^{2}=0,52$. Subordinadamente se encontra o $\mathrm{CO} 3+\mathrm{HCO} 3$ com $\mathrm{R}^{2}=0,43$. 


\section{4- CONCLUSÕES}

Conclui-se que dos vinte e sete poços estudados, apenas três (P-12, P-16 e P-26) não estão em conformidade com os parâmetros da portaria MS 2914/2011 de sulfato, sódio, turbidez, nitrato e nitrito. Portanto, de maneira geral, os poços da bacia hidrográfica do rio Grande estão compatíveis com os parâmetros necessários para classificar suas águas como potáveis, e indicadas para o consumo humano. A maioria destes poços foi identificada geologicamente com o Grupo Bambuí. Foi possível identificar também os dois melhores poços (P-18 e P-19) e relaciona-los com sua geologia, sendo que o primeiro está associado ao Grupo Santo Onofre e o segundo ao Grupo Bambuí. Estes estão contidos geomorfologicamente na unidade de Patamares e são classificados como propícios para irrigação, e sendo possível relacionar este relevo a boa qualidade de água subterrânea e de possíveis regiões favorável à captação de água destinada a irrigação.

\section{5- REFERÊNCIAS}

ALMEIDA, W.A; MOREIRA, C.M., 2014. Análise das outorgas da bacia do rio grande, Estado da Bahia. p.02-03.

ANA - Agência Nacional de Águas. Dados de estações fluviométricas. Disponível em: <http://www.snirh.gov.br/hidroweb/>. Acesso em: 06 de maio de 2016.

AIBA - Associação de Agricultores e Irrigantes da Bahia. Anuário da Região Oeste da Bahia,. 2008/2009. Barreiras: Editora Gazeta Santa Cruz. 48 p.

CPRM - Serviço Geológico do Brasil. Sistema de Informações de Águas Subterrâneas (SIAGAS). Disponível em: <http://siagasweb.cprm.gov.br/layout/pesquisa_complexa. php>. Acesso em: 06 de maio de 2016.

FUNCEME - Fundação Cearense de Meteorologia e Recursos Hídricos., 2007. Disponível em: <http://www.funceme.br/produtos/manual/projetos/qualigraf/>. Acesso em: 10 de junho de 2016.

IBGE - Instituto Brasileiro de Geografia e Estatística. IBGE Cidades@., 2007. Disponível em: < http://cidades.ibge.gov.br/xtras/home.php>. Acesso em: 26 de janeiro de 2010. 
INEMA - Instituto do Meio Ambiente e Recursos Hídricos. Relatório de Monitoramento da Qualidade das Águas - Primeira Campanha Trimestral. Salvador: INEMA, 2008. Disponível em: < http://www.inema.ba.gov.br/servicos/monitoramento/qualidade-dos-rios/relatorios-do-monitora/> . Acesso em: 09 de maio de 2016.

JUNIOR, A.V; LIMA, D.L.A.O., 2007. Avaliação hidrogeológica do aqüífero Urucuia na bacia do rio das Fêmeas - BA usando resistividade e polarização elétrica induzida. UFBA. p. 02-03.

LEAL,R,L et al., 2003. Definição de unidades geomorfológicas a partir de imagens de dados morfométricos na bacia do rio grande (BA). p.2056

MINISTÉRIO DA SAÚDE - Portaria 2914 / 2011., 2011. Disponível em: < http://bvsms.saude.gov.br/bvs/saudelegis/gm/2011/prt2914_12_12_2011.html>. Acesso em: 04 de maio de 2016.

MOREIRA, C. M; SILVA, D. D., 2010. Atlas Hidrológica da Bacia Hidrográfica do Rio Grande. Barreiras. p.07-15

PREFEITURA LEM - Prefeitura de Luis Eduardo Magalhães. Disponível em: Prefeitura de São Desidério - <http://saodesiderio.ba.gov.br/>. Acesso em: 08 de junho. de 2016.

SIMÕES, M., 2008. Métodos instrumentais para análise química quantitativa de águas subterrâneas e sua aplicação na caracterização do sistema aquífero Cenozóico do baixo Tejo em Almada. P. 0708 . 